\title{
Is Periodontal Disease a Red Flag for Breast Cancer Among Postmenopausal Female Smokers? An Update of the Last Decade
}

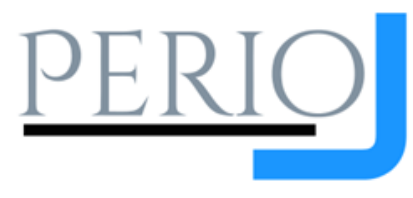

\section{Neelam Das}

Department of Periodontology, Rama Dental College,

Accepted for publication:

Hospital \& Research Centre, Kanpur, Uttar Pradesh, India.

\begin{abstract}
Periodontal disease is characterized by a chronic inflammation produced in response to a disease-associated, multispecies bacterial community in the subgingival region. In recent years, interest has focused on the potential role of periodontal disease in cancer pathogenesis. In this review, we presented a summary showing a strong association between breast cancer and poor oral health, presence of periodontitis-associated bacteria, tooth loss, and clinical signs of periodontitis. Proinflammatory pathways are activated either by mono- or polymicrobial infections, resulting in an increase in the expression of proinflammatory molecules such as interleukin (IL)-6, IL-8, IL-1 $\beta$, and tumor necrosis factor (TNF)- $\alpha$. In addition, it has been shown that several periodontitis-associated species induce the expression of genes related to cell proliferation, cell cycle, apoptosis, transport, and immune and inflammatory responses. Intriguingly, many of these pathways are linked to carcinogenesis. Among them, the activation of Toll-like receptors (TLRs) and antiapoptotic pathways (such as the phosphoinositide-3-kinaseprotein kinase B/Akt [PI3K-PKB/Akt], Janus kinase/signal transducers and activators of transcription [JAK/STAT], and mitogen-activated protein kinase [MAPK] pathways), the reduction of proapoptotic protein expression, the increase in cell migration and invasion, and the enhancement in metastasis are addressed. Cigarette smoking is one of the major causes of carcinogenesis. The incidence of breast cancer is increasing worldwide, making it the most common type of cancer among women. The etiology of breast cancer is multifactorial and cigarette smoking is one of the risk factors that has recently been shown to be associated with breast cancer. The relationship between cigarette smoking and breast cancer is due to one of the important components of cigarette smoke, 4-(methylnitrosamino)-1-(3-pyridyl)-1-butanone (NNK), which is a representative carcinogen of $\mathrm{N}$-nitrosamines that has gained focus in breast cancer carcinogenesis. The purpose of this review is to investigate the relationship between breast cancer and chronic periodontal disease changes that can occur at the oral level, including alterations of the oral microbiome, and pathological conditions among postmenopausal female smokers. Chronic periodontal disease and tooth loss were highly prevalent in postmenopausal breast cancer survivors. Based on this traditional review, the importance of dentists is clear in proposing to patients with breast cancer appropriate therapies and dedicated prevention sessions.
\end{abstract}

Keywords: Breast cancer; periodontal disease; inflammation; tooth loss

\section{Introduction}

It is now proven that periodontal diseases are associated with systemic conditions. The interactions that develop between periodontal bacteria and the oral cavity are multiple and very complex. More than 120 medical conditions, some of which are life threatening, can be detected and treated in the early stages by periodontists. ${ }^{1}$ There is a growing body of evidence suggesting a relationship between periodontal disease, cigarette smoking, and increased breast cancer risk.

Periodontal disease is characterized by a chronic inflammation produced in response to a disease-associated 
multispecies bacterial community in the periodontium. ${ }^{2}$ Although the inflammatory processes occur locally in the oral cavity, several studies have determined that inflammatory mediators produced during periodontitis, as well as subgingival species and bacterial components, can disseminate from the oral cavity, therefore contributing to various extra-oral diseases such as cancer. ${ }^{3}$ Interestingly, cancers are highly influenced by both a direct carcinogenic effect of periodontitis-associated bacteria in either oral cells or in other body sites and inflammatory mediators migrating from the oral cavity. ${ }^{4}$ However, although increasing evidence links periodontitis and carcinogenesis, the fact that periodontitis is a polymicrobial disease has not been well addressed in the context of cancer. ${ }^{5}$ This is especially relevant when evaluating the direct carcinogenic effect exerted by oral bacteria, since combined species act locally in oral cells and also migrate from the oral cavity. Cancer is a leading cause of mortality worldwide and among the female-specific malignancies, breast cancer remains the most common cancer type in developed countries, accounting for one-third of newly diagnosed cancers. ${ }^{6}$ The incidence of breast cancer was registered from 1985 to 2001 according to the World Health Organization (WHO) International Classification of Diseases criteria. In the present review, I am reporting a strong association between breast cancer and poor oral health, presence of periodontitis-associated bacteria, tooth loss, and clinical signs of periodontitis.

In 2013, the WHO estimated that globally, $21 \%$ of adults were current smokers, including 250 million women and 1 billion men. ${ }^{7}$ Women account for $15.7 \%$ of all current smokers, most of whom live in midand low-income countries. The WHO has also estimated that smoking is the cause of death of about six million people each year. ${ }^{8}$ The current available knowledge about the relationship between some certain human cancers and smoking is based mainly on epidemiological studies. Not until recently has the association between cigarette smoke and breast cancer received much attention. Many epidemiological and preclinical studies have implicated that cigarette smoke is one of the risk factors for breast cancer. ${ }^{9}$ Cigarette smoke contains more than 4,000 components, of which over 70 have been classified as carcinogens by the International Agency for Research on Cancer (IARC). ${ }^{10}$ Several tobacco carcinogens that have been detected in the circulation of smokers are activated and metabolized into electrophilic intermediates by breast epithelial cells because of DNA adduct formation and DNA damage. ${ }^{11}$ Thus, much attention has been extended to breast cancer.

The purpose of the present review is to investigate the link between smokers' breast cancer and the periodontal disease changes that can occur at the oral level, including alterations of the oral microbiome and pathological conditions. The focus of this traditional review is on the epidemiological, biological, systemic, and genetic evidence that has accumulated particularly over the past decade, which supports a causal mechanism between periodontal disease and smokers' breast cancer.

\section{The Link Between Periodontal Disease and Cancer}

Several epidemiological and laboratory studies have reported that long-term inflammation promotes tumor development, growth, and progression. ${ }^{12}$ It has been confirmed that malignancies can arise from areas that are characterized by infection and inflammation as a part of the physiological immune response of the host. This observation suggests that chronic inflammation could be a risk factor for the development of a number of malignancies in humans, including in organs such as the breast. ${ }^{13}$ Persistent host infections are able to induce chronic inflammation in which leukocytes and other immune system phagocytes can induce DNA damage in proliferating cells through the production of toxic substances such as reactive oxygen species (ROS) and reactive nitrogen intermediates (RNI) that under normal conditions are produced by those cells for the control of the infection. ${ }^{14}$ These species react to the formation of peroxynitrate which is a mutagenic agent. Consequently, a repeated tissue injury and the regeneration of 
the damaged tissue in the presence of elevated levels of ROS and RNI released by inflammatory cells, causing those reactive species to be involved in oxidative DNA damage in proliferating epithelial cells leading to permanent alterations in the genome, such as point mutations, chromosomal deletions, or rearrangements. ${ }^{14}$

The link between inflammatory response and cancer has been considered to consist of two mechanisms, an exogenous and an endogenous. According to the exogenous mechanism, a chronic inflammatory response is able to increase the risk of cancer, while in the endogenous, acquired genetic alterations can trigger tumor development and growth. ${ }^{15}$ Chronic inflammation can stimulate the development of malignant tumors of epithelial origin due to an indirect mechanism that involves the activation of local inflammatory cells. This process can also lead to the exposure of proliferating epithelial cells to mutagen factors. Microorganism products that relate to inflammation are able to activate host cells, such as inflammatory response cells, tissue fibroblasts, and epithelial cells to produce a wide spectrum of toxic substances that are able to cause damage to the epithelial cell DNA. Chronic inflammatory responses are often associated with the release of large amounts of cell substances such as chemokines, growth factor agents, cytokines, and other species that can create a suitable environment for cellular survival, cell proliferation and migration, promotion of angiogenesis, and inhibition of apoptosis. This environment can cause the epithelial cells to accumulate mutations and lead those mutant cells to proliferate and migrate and can provide opportunities for the development and growth of those cells. ${ }^{16}$ The highest incidence of cancer being in individuals with chronic inflammation was the basis for investigating the probability of correlation with periodontitis. ${ }^{17}$

The Specific Role of Periodontal Disease in the Pathogenesis of Breast Cancer in Smokers
The association is biologically possible and could be interpreted on the basis of the following mechanisms: ${ }^{18}$

a. The disrupted mucosal barrier in cases of periodontal disease causes an enhanced carcinogen penetration, as with smoking.

b. The cell load increases in the blood vessels and the connective tissue in case of a chronic inflammatory response. The relationship between chronic inflammation and cancer is associated with the development of a chronic diffuse hyperplasia of the epithelial cells that is considered a common precursor of intraepithelial neoplasia.

c. Immunosuppression is a common mechanism that leads to periodontal disease and cancer.

d. A bacterial overgrowth may occur due to poor oral hygiene leading to an increase in the percentage of metabolites with a potential carcinogenic effect.

e. With common genetic risk factors, such as in dizygotic twins, the classic periodontal disease leads to a significantly increased risk for cancer development, whereas in monozygotic twins this association is significantly impaired. ${ }^{19}$

\section{The Mechanism of Cancer Promotion by Periodontitis-Associated Bacteria}

Although the exact mechanisms involved in cancer promotion by periodontal bacteria have not been completely elucidated, local inflammatory effects triggered by bacterial infection have been associated with cellular transformation (Figure 1). 5,20

\section{Hypotheses on the Relationship Between Periodontal Disease and Cancer}

\section{A. Alteration in Oral Microflora}

From a periodontal point of view, a wide variety of oral microorganisms, oral bacteria, and their metabolic products, such as endotoxins and enzymes that are toxic to the surrounding cells and tissues, may directly induce mutations in tumor suppressor genes and proto-oncogenes or alter cellular signaling pathways that affect epithelial cell survival or cellular proliferation (Figure 2). ${ }^{21,22}$ 


\section{B. Periodontitis, Inflammatory Load, and Predisposition for Carcinogenesis}

Periodontitis causes the release of cytokines, chemokines, prostaglandins (PGs), bacterial toxins, endotoxins, and enzymes from the host's cells which have destructive effects on periodontal tissue including periodontal pocket formation and alveolar bone destruction. ${ }^{23}$ Proinflammatory cytokines such as tumor necrosis factor (TNF)- $\alpha$, interleukin (IL)- $1 \beta$, interferon (IFN)- $\gamma$ and PGE2 are present in elevated levels in periodontitis. Periodontal tissue may act as a refreshment tank for the leakage of those mediators causing them to enter the blood circulation leading to systemic effects. ${ }^{24}$
A link between periodontal disease and cancer has been recorded in a population of health professionals and the conclusion was that the mechanisms that are associated with the inflammatory load due to systemic inflammation, and the increased concentrations of carcinogenic products subsequent to inflammatory processes in response to the oral pathogens, could contribute to the development of cancer. ${ }^{25}$ Periodontitis may be a substitute indicator for the effects of smoking. It is relevant that cigarette smoking is responsible for oxidative stresses and activates processes that could contribute to epithelial cell transformation, whereas the degree of periodontal inflammatory load would be an important factor in triggering a systemic effect (Figure 3). ${ }^{26,27}$

Figure 1. Host response mechanisms of cellular transformation induced by periodontopathic bacteria

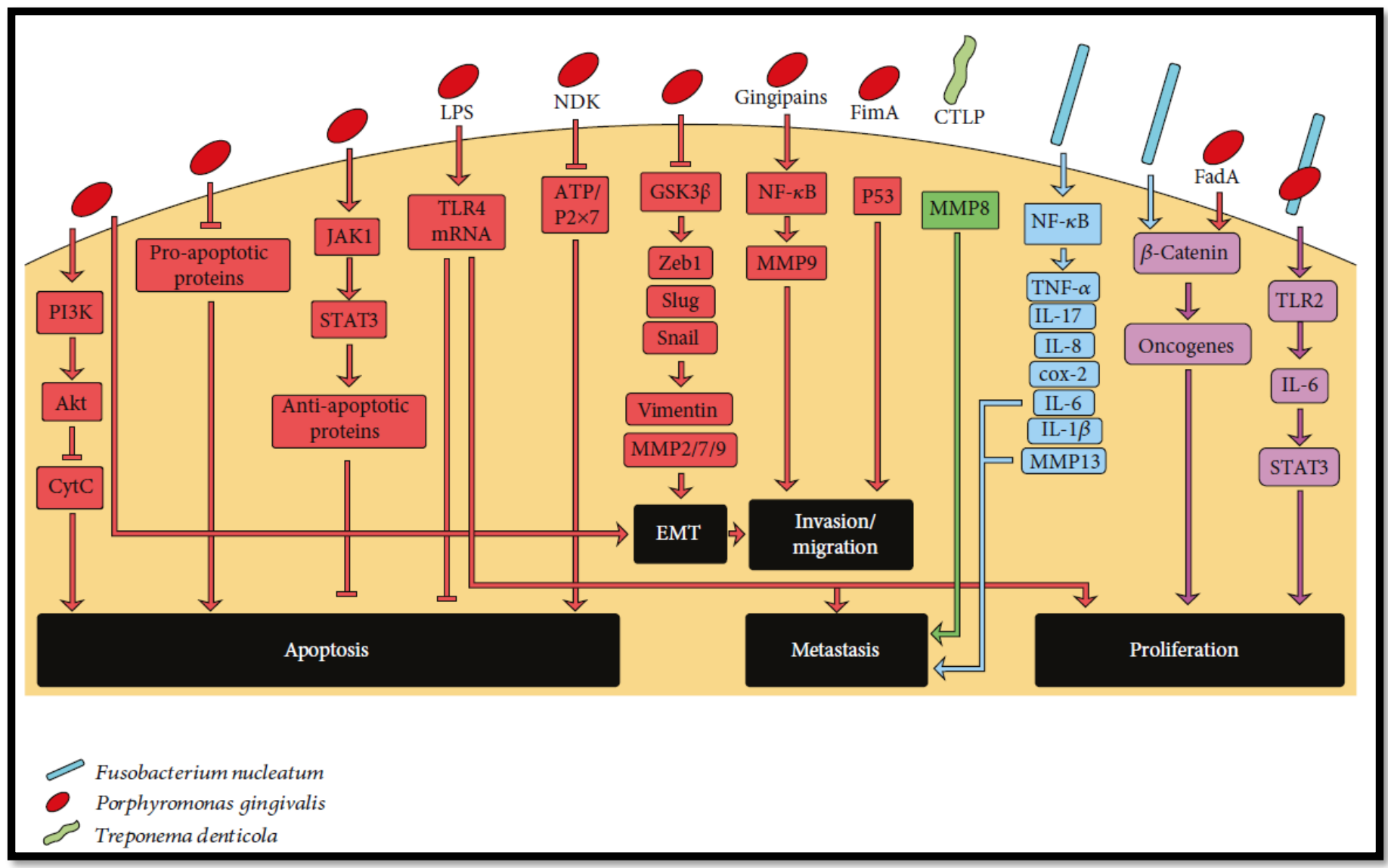

Inhibition of apoptosis, epithelial-mesenchymal transition (EMT), invasion and migration, metastasis, and proliferation are triggered through the activation of prooncogenic pathways by $P$. gingivalis (red arrows), $T$. denticola (green arrow), F. nucleatum (blue arrow), and $P$. gingivalis + F. nucleatum coinfection (purple arrows).

\section{Genetic Factors}

Common underlying genetic factors may increase the host's susceptibility to both periodontal disease and cancer or may alter the relationship of environmental factors, such as smoking, with both conditions. However, the common genetic risk factors' role between the two conditions remains 
unclear. Predetermined factors such as genetic polymorphisms could be involved in the sensitivity of the disease. As has already been reported, an inflammatory response may play a role in some cancers, and it is possible that the genetic polymorphisms that are related to an increased periodontal disease risk are also of vital importance in cancer development (Figure 4). ${ }^{28,29}$

Figure 2. An outline of NNK-induced signaling pathways

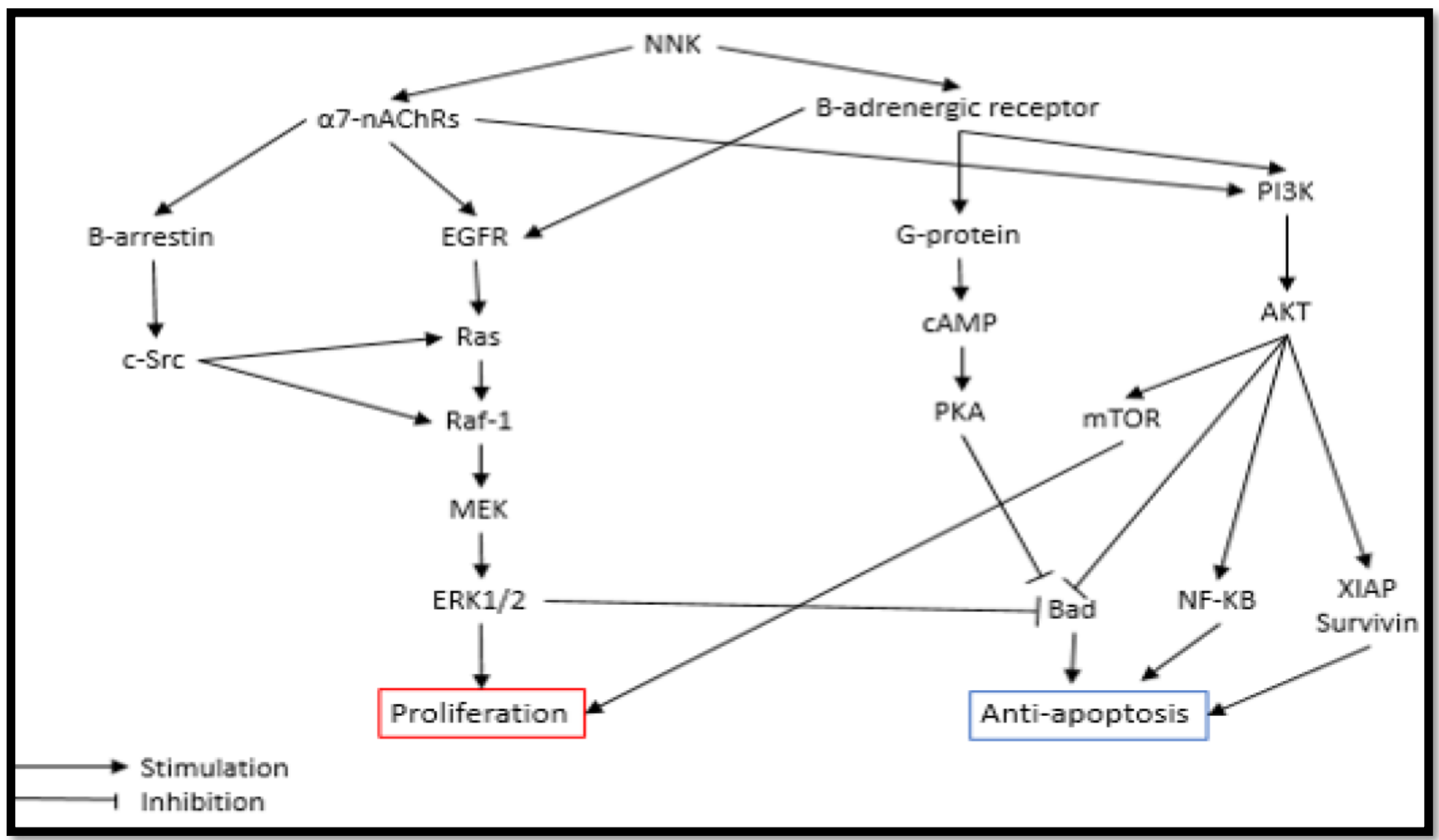

\section{Prevalence of Breast Cancer}

Breast cancer is the most common malignancy in women worldwide and the leading cause of death among women. ${ }^{30}$ According to recent estimates, 1.38 million women were diagnosed with breast cancer and 485,000 died worldwide in 2019. ${ }^{31}$ Breast cancer is one of the most frequently diagnosed cancers among women in economically developing countries. ${ }^{32}$ In the year 2020 more than 1.5 million new cases of breast cancer have been reported globally and the incidence has increased by $20.0 \%{ }^{33}$ In a cancer research, it was reported that women from the United Kingdom and the United States were observed to be at a higher risk, with a rate of more than 120 per 100,000 population. ${ }^{34}$ In contrast, India, China, and South Africa have a considerably lower incidence rate of about 30 per 100,000 population. Overall, a five year survival rate is observed among $80-90 \%$ of patients from the United Kingdom and the United States and is only up to $50-60 \%$ among patients from India, Thailand, and Malaysia. ${ }^{35}$ In India, breast cancer is the most common cancer diagnosed among women, accounting for nearly 1 in 3 cancers, and is the second leading cause of cancer death among women after lung cancer. ${ }^{7}$ Over 200,000 women are diagnosed with breast cancer annually in India. Breast cancer occurs more frequently in postmenopausal women at the age of 61 years. Although the etiology of most breast cancers is unknown, some risk factors have been established such as gender, age, family history, late menopause, early menarche, ethnicity, and genetic risk factors..$^{36}$ On the other hand, an important decrease in mortality due to breast cancer has been observed in recent years due to the development of new adjuvant therapy and screening programs. ${ }^{37}$ As breast cancer is undoubtedly a very serious and widespread problem, it is important to evaluate if there is a correlation between oral diseases and this type of tumor as a means of further defence against this pathological condition.

The Relationship Between Periodontitis and Breast Cancer 
Periodontal disease is characterized by chronic infection and inflammation of periodontal tissue leading to the destruction of alveolar bone surrounding the teeth. The relationship between periodontitis and breast cancer has been widely investigated through several works.
In 2011, Soder et al. conducted a prospective study of 3,273 women randomly selected between the ages of 30 and 40 years for a period of approximately 16 years. The study showed that women with periodontitis and with missing molars had a higher risk of developing breast cancer. ${ }^{16}$

Figure 3. Flow chart explaining the mechanism of cancer progression from periodontopathogenic bacteria and periodontal disease

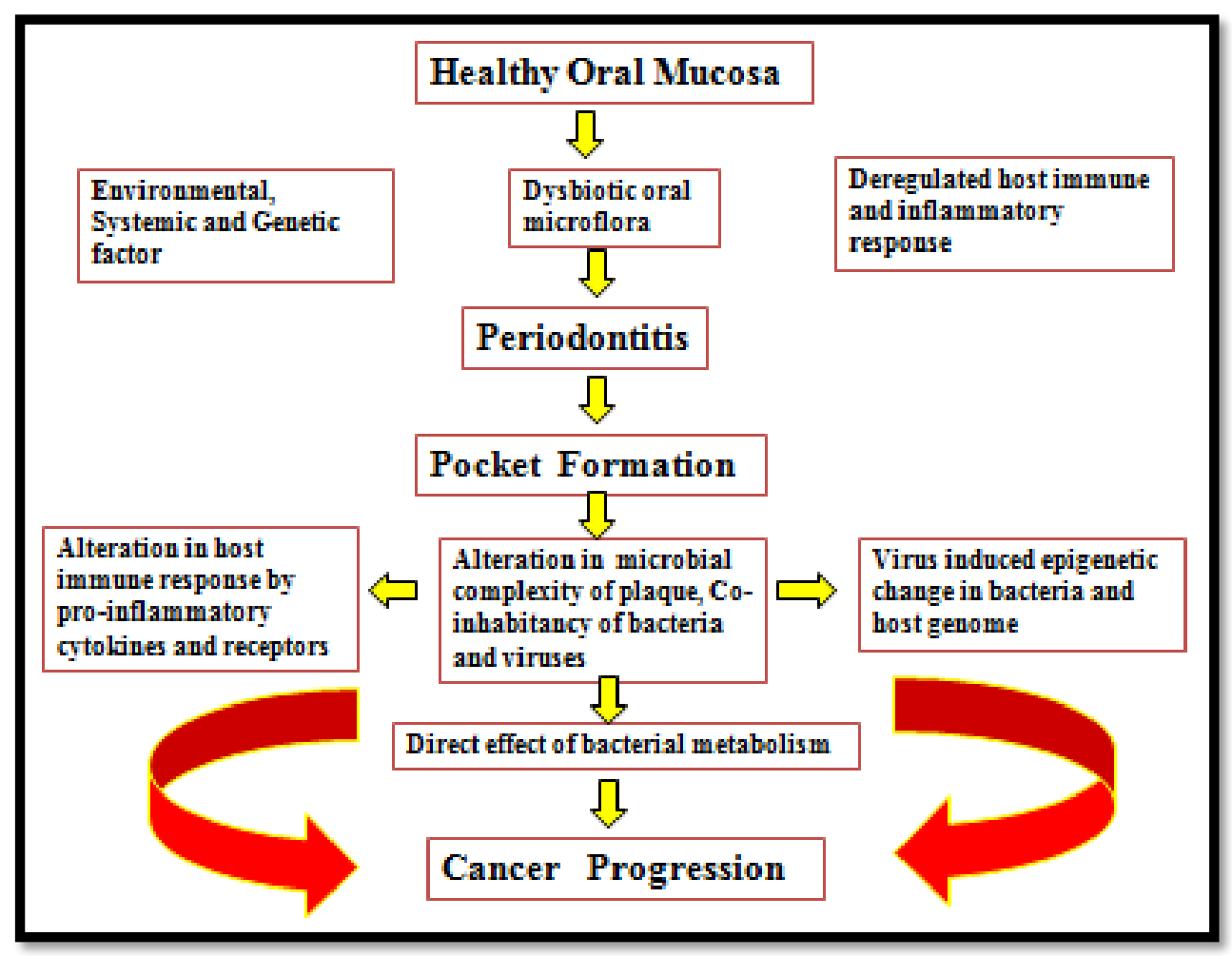

Figure 4. Flow chart summarizing the simplified molecular mechanism of cancer progression by periodontitis-associated bacteria and other periodontal risk factors

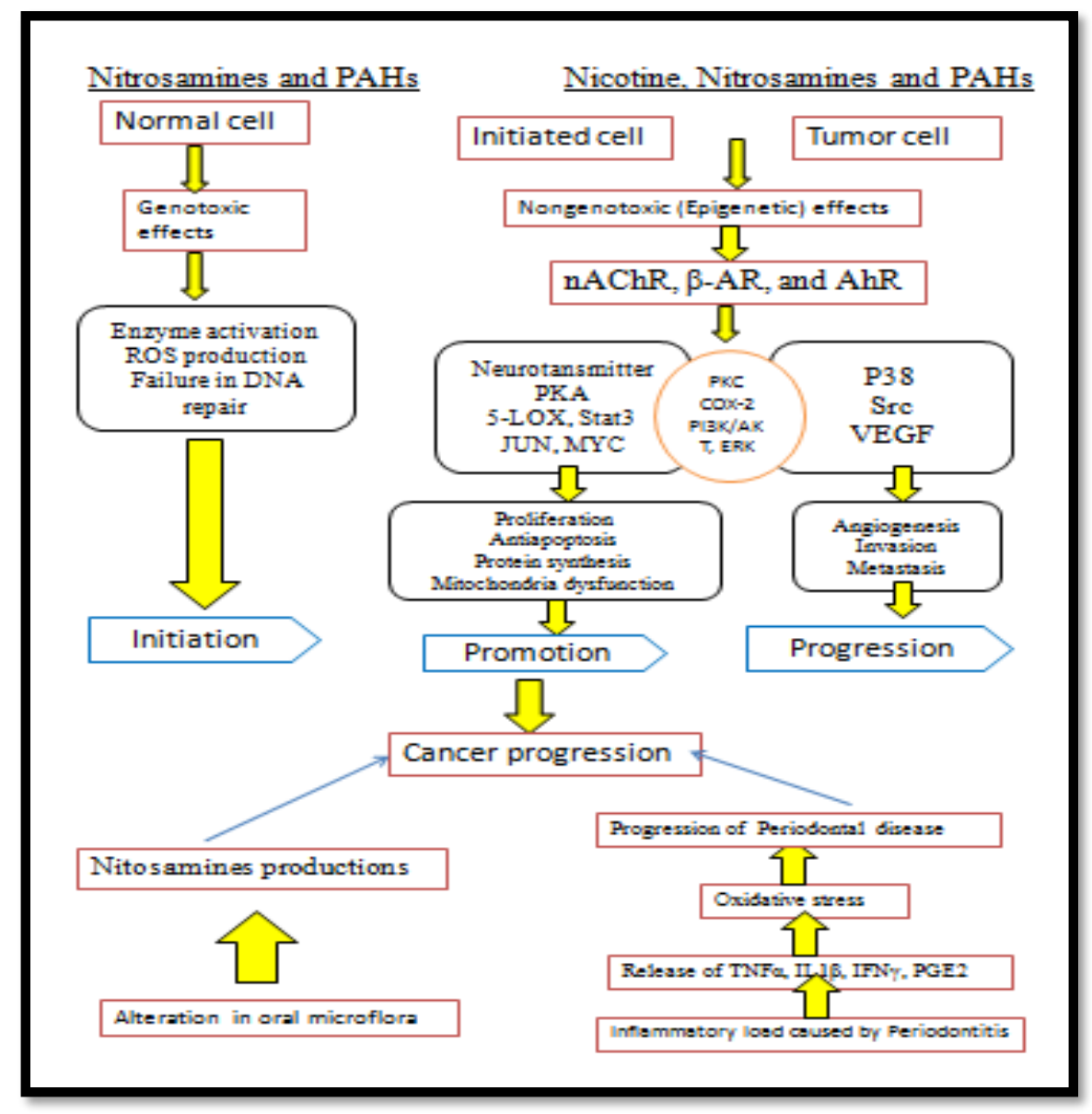


Virtanen et al. examined the association between periodontitis and breast cancer risk in 2009 and found that $6.3 \%$ of the 286 recruited subjects with periodontal disease also had cancer. Moreover, it was observed that the risk of cancer was greater if the first mandibular molar was missing, compared to the second mandibular molar. ${ }^{38}$ This association also seems to have been confirmed through a study by Freudenheim et al. who reported an increased risk of breast cancer among more than 93,000 postmenopausal women with a history of periodontitis, especially in former smokers who quit in the previous 20 years. ${ }^{39}$

Sfreddo et al. also reported a link between periodontitis and breast cancer in a sample of adult Brazilian women. They observed that cases had significantly greater clinical attachment loss than controls. Women diagnosed with periodontitis had two to three times higher odds of breast cancer than women without periodontitis. They concluded that a significant association was observed between periodontitis and breast cancer. ${ }^{40}$

Shi et al. conducted a meta-analysis of 8 studies which included 168,111 subjects and explored the connection between periodontal disease and breast cancer. They showed that periodontal disease did increase susceptibility to breast cancer with robust results confirmed by sensitivity analysis $(\mathrm{RR}=1.18, \mathrm{Cl} 95 \%: 1.11-1.26) .{ }^{41}$

In another systematic review, Nwizu et al. initially examined just under 500 articles to understand the role of periodontitis in cancer development in various sites, including breast cancer. An association was found between periodontal disease and the breast neoplasms (RR = 1.11; CI 95\%: 1.00-1.23). ${ }^{42}$

Amodio et al. conducted a casecontrol study in which they assessed the prevalence of periodontal disease in 48 postmenopausal patients following cancer treatment, compared to 48 controls without cancer. They detected a high prevalence of periodontitis in postmenopausal survivors (98\% in breast cancer survivors and $87 \%$ in controls). The results found are therefore oriented in two directions; on the one hand, patients with periodontitis had an an increased risk of developing breast cancer, and on the other hand, a greater prevalence of periodontitis was observed in treated cancer patients. ${ }^{43}$

A possible explanation is that periodontal disease is associated with an increased production of reactive oxygen species which cause damage to the host cells and tissues. The by-products of the oral inflammation enter the bloodstream, which may enhance cellular proliferation and mutagenesis and allow for the development and spread of cancer. Some studies have also described that some polymorphisms of Toll-like receptor (TLR) genes are associated with not only a greater susceptibility to periodontitis, but to several types of cancer as well. ${ }^{44}$ It is opportune to observe how the lowering of the immune defences due to cancer and its treatments can be a factor favouring the development of periodontal disease.

\section{Association of Cigarette Smoking with Breast Cancer Risk}

To clarify our understanding of the relationship between cigarette smoking and breast cancer risk we examined the association using data from the National Institutes of Health (NIH) study, a large prospective cohort study that has previously demonstrated breast cancer risk relationships for a variety of factors that could potentially confound or modify associations with cigarette smoking. ${ }^{45}$ Additionally, we examined whether smoking was related to the risk of specific subgroups of breast cancer, defined by disease stage at diagnosis, histology, hormone receptor expression, and tumor grade.

Many epidemiological studies have revealed an association between smoking and breast cancer risk among women. Reynolds and Cui have demonstrated that breast cancer incidence was associated with cigarette smoking. ${ }^{46,47}$ A positive correlation between breast cancer risk and active cigarette smoking was observed, and current smokers had a higher risk of breast cancer than former smokers. Among them, 
those who smoked for more than 40 years showed a significant association with increased breast cancer risk than those who had a history of smoking for a smaller number of years. In 2005, the California Environmental Protection Agency (CaEPA) reviewed 52 studies and concluded that there was a positive correlation of breast cancer risk with active cigarette smoking. ${ }^{48}$ Furthermore, cigarette smoke also increased the risk of breast cancer among women who were postmenopausal.

\section{The Possible Biological Mechanisms} Explaining How Cigarette Smoking Increases the Risk of Breast Cancer Among Postmenopausal Women

The association of smoking with increased risk of breast cancer is biologically plausible, especially when exposure occurs during certain critical periods. Pubertal breast development generally begins prior to menarche and marks a time of increased epithelial cell proliferation. As such, this may be a critical time for susceptibility to carcinogens. Other investigations point towards the importance of the timing of smoking initiation in relation to reproductive development. Women who are BRCA1/BRCA2 mutation carriers at high risk of a specific type of familial breast cancer, which is consistent with the finding of smoking-associated risk among postmenopausal women. ${ }^{49}$ The potential mechanism that would result in a smokingassociated risk among these women could be hypothesized by the fact that smoking and a family history of breast cancer contribute to risk through the same pathway, and if that pathway is activated by factors like family history there can be further activation by smoking. A greater exploration of the role of genetic factors in smoking associated breast carcinogenesis is needed to understand the possible effect of modification by family history.

Human biomarker studies have also strongly suggested that breast tissue is a target for the carcinogenic effects of cigarette smoke..$^{50}$ It was found that DNA adducts (DNA covalently bonded to a carcinogenic chemical) with derivatives of cigarette smoke are more common in the breast tissue of smokers than that of nonsmokers. ${ }^{51}$ The wide variation between people in DNA adduct formation and repair is likely related to a combination of factors, including the properties of individual carcinogens and host genetic polymorphisms. ${ }^{52}$ In 1996, Ambrosone et al. reported that postmenopausal women who smoked and had the slow acetylator genotype for $\mathrm{N}$-acetyltransferase 2 (NAT 2) had a significantly elevated risk for breast cancer. ${ }^{53}$

Breast cancer is a heterogeneous disease that may vary in its etiologies. Current data suggest that cigarette smoking is more strongly associated with lobular cancer than with ductal cancer and with tumors that are hormone receptor positive for both estrogen and progesterone than the other three combinations of receptor status. One study that examined smoking in relation to the risk of different histological subtypes of breast cancer among postmenopausal women reported that recent smoking had a borderline association with the risk of ductal cancer (odds ratio 1.2 [95\% confidence interval 1.0 to 1.4]) but not with other histological types. ${ }^{54}$ The findings suggesting a particular association with lobular cancer should be considered preliminary.

The relationship between cigarette smoking and breast cancer is due to one of the important components of cigarette smoke, 4-(methylnitrosamino)-1-(3-pyridyl)1 -butanone (NNK), which is a representative carcinogen of $\mathrm{N}$-nitrosamines. Moreover, it has been suggested that cigarette smoking plays a role in contributing to DNA alterations in postmenopausal breast cancer patients. Although increasing evidence points to the potentiating effect of cigarette smoking on the development of breast cancer, there are still some controversies on its significance. ${ }^{55}$

\section{The Active Component in Cigarette Smoke is NNK}

More than 60 known carcinogens have been identified in cigarette smoke, among which nicotine-derived nitrosamine ketones (NNK) have gained much attention in cancer initiation and promotion. ${ }^{56}$ In fact, the IARC 
has classified NNK as a carcinogen in 2007. The level of NNK varies in different cigarette brands and it ranges from 53.5-220.7 $\mathrm{ng} /$ cigarette in mainstream smoke and 50.7$96.7 \mathrm{ng} / \mathrm{cigarette}$ in sidestream smoke. ${ }^{10}$ Among all tobacco-specific nitrosamines, NNK has been proven to cause lung cancer in humans and animals. ${ }^{56}$

\section{The Effect of NNK in Breast Cancer Progression}

The effect of NNK on breast cancer initiation has been studied in normal breast cells. Treatment with NNK on breast epithelial cell line MCF-10A showed malignant transformation with over expression of a7and a9-nicotinic acetylcholine receptors (nAChRs). NNK upregulated extracellular signal-regulated kinase $1 / 2$ (ERK1/2) phosphorylation, stimulated expression of hepatocyte growth factor (HGF), and downregulated the expression of tumor suppressor gene CDKN2A. ${ }^{57}$ MCF-10A cells treated with a combination of NNK and benzo[a]pyrene (B[a]P) induced breast cancer carcinogenesis through DNA damage, Ras-ERK-Nox signalling activation, and reactive oxygen species elevation. ${ }^{58} \mathrm{By}$ profiling gene expressions using cDNA microarray, NNK regulated several important breast cancer related genes including downregulation of PCSK2, TUBB2C, and S100A2 and upregulation of CRYAB, HSD11B2, FLJ20366 and TRIM29. ${ }^{59}$ In addition, NNK is capable of inducing malignant transformation of noncancerous breast epithelial cells, accompanied by a loss of responsiveness to $17 \beta$-estradiol via the ERK-dependent pathway. ${ }^{60}$

\section{Formation of DNA Adducts in Smoking Breast Cancer Patients}

Cigarette smoke is known to cause DNA adducts and mutations inducing tumor growth in humans. ${ }^{61}$ DNA adduct formation is considered as a critical step during tumor initiation. Among smokers who were passively exposed to second-hand smoke, electrophilic metabolic forms of tobacco components were detected in breast epithelial cells, which bound to DNA and formed DNA adducts. ${ }^{62}$ This phenomena is shown in both cancerous and normal breast tissue. Evidence showed that mutagens including prochlorperazine from exogenous sources were detected in the breast fluid of postmenopausal women. Also, cigaretteinduced DNA adducts were identified in normal breast tissues in smokers with breast cancer. Smokers had a higher prevalence of TP53 mutations than non-smokers. ${ }^{49}$ The benzopyrene caused genomic alteration in breast epithelial cells following exposure to smoking showed similar levels with those seen in familial breast cancer cells. The action of cytochrome P450 plays an important role in NNK metabolism to form Nnitrosonornicotine (NNN) and 4(methylnitrosamino)- 1-(3-pyridyl)-1-butanol (NNAL). These metabolites induce pyridylhydroxybutylation,

pyridyloxobutylation, and methylation of nucleobases inside the nucleus. Subsequently, NNK metabolites bind to DNA and change into the covalent binding forms named DNA adducts. ${ }^{63}$

\section{Progression of NNK Mediated Signaling Pathways in Smoking Breast Cancer Patients}

Smoke components have been proven to cause DNA alteration through various signaling pathways (Figure 2). ${ }^{22}$ As NNK is an agonist for nAChRs, most of the effects are mediated by the binding to nAChRs, such as a9- or a7-nAChRs, to cause proliferation, apoptosis, migration, invasion, angiogenesis, and chemoresistance. NNK activates the protein kinase $C$ (PKC), ERK1/2, protein kinase $A(P K A)$, or protein kinase B (Akt) pathways, or activates Bcl-2, $\mathrm{Mcl}-1$, and $\mathrm{C}-\mathrm{Myc}$, or suppresses Bad and Bax, to induce proliferation and apoptosis. ${ }^{64}$ On the other hand, activation of ERK activates calpains and suppresses $\mathrm{E}$ cadherin, $\beta$-catenin, or ZO-1 to promote migration. NNK increases the influx of $\mathrm{Ca}^{2+}$ to activate PKA, vascular endothelial growth factor (VEGF), and fibroblast growth factor 2 (FGF2) for angiogenesis in smoking breast cancer patients. ${ }^{65}$

\section{Conclusion and Future Perspectives}

Although carcinoma of the breast affects a region other than the mouth, it causes 
several problems at the oral level. It may act in a direct way by weakening the immune system, and thereby increasing the risk of developing periodontal disease. Breast cancer therapy also has different effects on the oral cavity that the periodontist must know. From this review, we can clearly understand the relationship between periodontal disease and smokers' breast cancer, thereby raising our awareness of the importance of oral health maintenance, which may lead to a reduced risk of developing breast cancer.

Frequent professional oral hygiene sessions can reduce the risk of developing periodontal disease and with the use of artificial saliva and a diet low in fermentable sugars risk of caries can be reduced. ${ }^{66}$ Patients undergoing hormone therapy may have bone loss, and a periodontist must know this possibility and monitor the condition by assessing the possible need for anti-osteoporosis therapy. ${ }^{67}$ Chemotherapy modifies the oral microbiome of the patient and an assessment of the cariogenic species through appropriate instrumental tests can be performed periodically to investigate these bacteria early before signs of caries begin to appear. ${ }^{66}$ Periodontists should be aware of these disorders resulting from the therapy of breast cancer in order to inform patients about any alterations they might have. As regards to periodontal disease, most researchers who have investigated the correlation with breast cancer have also mentioned that better conducted studies would be needed with comparable and standardized protocols along with more accurate sampling methods.

\section{References}

1. Singh $H$, Singh $S$. Oral and systemic health. In: Saini R, Saini S, editors. Dental Horizons: Essentials of oral health. $1^{\text {st }}$ ed. Hyderabad: Paras Medical Publishers; 2011. p. 259-73.

2. Abusleme L, Dupuy AK, Dutzan N, et al. The subgingival microbiome in health and periodontitis and its relationship with community biomass and inflammation. ISME J. 2013 May; 7(5):1016-25. https://doi.org/10.1038/ismej.2012.174
3. Mawardi HH, Elbadawi LS, Sonis ST. Current understanding of the relationship between periodontal and systemic diseases. Saudi Med J. 2015 Feb; 36(2):150-8.

https://doi.org/10.15537/smj.2015.2.9424

4. Fitzpatrick SG, Katz J. The association between periodontal disease and cancer: a review of the literature. J Dent. 2010 Feb;

38(2):83-95. https://doi.org/10.1016/j.j.dent.2009.10.0 07

5. Atanasova KR, Yilmaz O. Looking in the Porphyromonas gingivalis cabinet of curiosities: the microbium, the host and cancer association. Mol Oral Microbiol. 2014 Apr; 29(2):55-66. https://doi.org/10.1111/omi.12047

6. Ganz PA, Goodwin PJ. Breast Cancer Survivorship: Where Are We Today? Adv Exp Med Biol. 2015; 862:1-8. https://doi.org/10.1007/978-3-319-163666_1

7. DeSantis C, Ma J, Bryan L, Jemal A. Breast cancer statistics, 2013. CA Cancer $J$ Clin. Jan-Feb 2014; 64(1):52-62. https://doi.org/10.3322/caac.21203

8. World Health Organization. WHO report on the global tobacco epidemic, 2015: Raising taxes on tobacco. Geneva: WHO Press, Switzerland. 2015.

9. Reynolds P. Smoking and breast cancer. J Mammary Gland Biol Neoplasia. 2013 Mar; 18(1):15-23. https://doi.org/10.1007/s10911-0129269-x

10. IARC Working Group on the Evaluation of Carcinogenic Risks to Humans. Smokeless Tobacco and Some Tobaccospecific $N$-Nitrosamines. Lyon (FR): International Agency for Research on Cancer.

2007; https://www.ncbi.nlm.nih.gov/books/NBK 326497/

11. MacNicoll AD, Easty GC, Neville AM, Grover PL, Sims P. Metabolism and activation of carcinogenic polycyclic hydrocarbons by human mammary cells. Biochem Biophys Res Commun. 1980 Aug 29; 95(4):1599-606. https://doi.org/10.1016/s0006291X(80)80081-7

12. Balkwill F, Mantovani A. Inflammation and cancer: back to Virchow? Lancet. 
2001 Feb 17; 357(9255):539-45.

https://doi.org/10.1016/S0140-

6736(00)04046-0

13. Kuper H, Adami HO, Trichopoulos D. Infections as a major preventable cause of human cancer. J Intern Med. 2000 Sep; 248(3):171-83.

https://doi.org/10.1046/j.1365-

2796.2000.00742.x

14. Maeda $H$, Akaike T. Nitric oxide and oxygen radicals in infection, inflammation, and Cancer. Biochemistry (Mosc). 1998 Jul; 63(7):854-65.

15. Shacter E, Weitzman SA. Chronic inflammation and cancer. Oncology (Williston Park). 2002 Feb; 16(2):217-26.

16. Söder B, Yakob M, Meurman JH, Andersson LC, Klinge $B$, Söder $P$. Periodontal disease may associate with breast cancer. Breast Canc Res Treat. 2011 Jun; 127(2):497-502. https://doi.org/10.1007/s10549-0101221-4

17. Coussens LM, Werb Z. Inflammation and cancer. Nature. 2002 Dec; 420(6917):860-7.

https://doi.org/10.1038/nature01322

18. Tezal M, Sullivan MA, Reid ME, et al. Chronic periodontitis and the risk of tongue cancer. Arch Otolaryngol Head Neck Surg. 2007 May; 133(5):450-4. https://doi.org/10.1001/archotol.133.5.45 0

19. Arora M, Weuve J, Fall K, Pedersen NL, Mucci LA. An exploration of shared genetic risk factors between periodontal disease and cancers: a prospective cotwin study. Am J Epidemiol. 2010 Jan; 171(2):253-9.

https://doi.org/10.1093/aje/kwp340

20. Hoare A, Soto C, Rojas-Celis V, Bravo D. Chronic Inflammation as a Link between Periodontitis and Carcinogenesis. Mediators Inflamm. 2019 Mar 27; 2019:1029857. https://doi.org/10.1155/2019/1029857

21. Zaris S, Bojic B, Jankovic LJ, et al. Periodontal therapy improves gastric Helicobacter pylori eradication. J Dent Res. 2009 Oct; 88(10):946-50. https://doi.org/10.1177/03000605188161 58

22. Guan Z, Cheuk IW, Shin VY, Kwong A. Is Smoking a Risk Factor of Breast
Cancer? NACS. 2019; 2(3):194-99. https://doi.org/10.31031/NACS.2019.02. 000540

23. Pihlstrom BL, Michalowics BS, Johnson NW. Periodontal diseases. Lancet. 2005; 366: $\quad 1809$ - 20. https://doi.org/10.1177/00220345093445 59

24. Page RC. The pathobiology of periodontal diseases may affect systemic diseases: inversion of a paradigm. Ann Periodontol. 1998 Jul; 3(1):108-20. https://doi.org/10.1902/annals.1998.3.1.1 08

25. Michaud DS, Joshipura K, Giovannucci E, Fuchs CS. A prospective study of periodontal disease and pancreatic cancer in US male health professionals. $J$ Natl Cancer Inst. 2007 Jan; 99(2):171-5. https://doi.org/10.1093/jnci/djk021

26. Hujoel PP, Drangsholt M, Spiekerman C, Weiss NS. An exploration of the periodontitis-cancer association. Ann Epidemiol. 2003 May; 13(5):312-6. https://doi.org/10.1016/s1047-

2797(02)00425-8

27. Chrysanthakopoulos NA. Periodontal Disease - Cancer Association and the Specific Role of Periodontal Disease in Lung Cancer Pathogenesis. $M J$ Dent. 2018; 3(1):1-11.

28. Kamangar F, Cheng C, Abnet CC, Rabkin CS. Interleukin-1B polymorphisms and gastric cancer risk--a meta-analysis. Cancer Epidemiol Biomarkers Prev. 2006 Oct; 15(10):1920-8. https://doi.org/10.1158/1055-9965.EPI06-0267

29. Chen RJ, Chang LW, Lin P, Wang YJ. Epigenetic Effects and Molecular Mechanisms of Tumorigenesis Induced by Cigarette Smoke: An Overview. J Oncol. 2011; 2011:1-14. https://doi.org/10.1155/2011/654931

30. Minatoya M, Kutomi G, Asakura S, et al. Equol, adiponectin, insulin levels and risk of breast cancer. Asian Pac J Cancer Prev. 2013; 14(4):2191-9. https://doi.org/10.7314/apjcp.2013.14.4.2 191

31. Jemal A, Bray F, Center MM, Ferlay J, Ward E, Forman D. Global cancer statistics. CA Cancer J Clin. 2011 Mar- 
Apr;

61(2):69-90.

https://doi.org/10.3322/caac.20107

32. Ferlay J, Shin H, Bray F, Forman D, Mathers C, Parkin DM. Estimates of worldwide burden of cancer in 2008: GLOBOCAN 2008. Int J Cancer. 2010 Dec 15; 127(12):2893-917. https://doi.org/10.1002/ijc.25516

33. Breast cancer statistics. Cancer Research UK Website. https://www.cancerresearchuk.org/health -professional/cancer-statistics/statisticsby-cancer-type/breast-cancer. Accessed April 3, 2020.

34. Siegel R, Ma J, Zou Z, Jemal A. Cancer statistics, 2014. CA Cancer J Clin. 2014 Jan-Feb; 64(1):9-29. https://doi.org/10.3322/caac.21208

35. Abdullah NA, Mahiyuddin WRW, Muhammad NA, et al. Survival rate of breast cancer patients in Malaysia: a population-based study. Asian Pac $J$ Cancer Prev. 2013; 14(8):4591-4. https://doi.org/10.7314/apjcp.2013.14.8.4 591

36. Taichman LS, Griggs JJ, Inglehart MR. Periodontal health, perceived oral health, and dental care utilization of breast cancer survivors. J Public Health Dent. 2015; 75(2):148-56. https://doi.org/10.1111/jphd.12084

37. Berry DA, Cronin KA, Plevritis SK, et al. Effect of screening and adjuvant therapy on mortality from breast cancer. $N$ Engl $J$ Med. 2005 Oct; 353(17):1784-92. https://doi.org/10.1056/NEJMoa050518

38. Virtanen $E$, Söder $P$, Meurman $J H$, Andersson LC, Söder B. Chronic Periodontal Disease: A Proxy of Increased Cancer Risk. Int J Cancer Res. 2013 Apr; 47(1):1127-33.

39. Freudenheim JL, Genco RJ, LaMonte $\mathrm{MJ}$, et al. Periodontal disease and breast cancer: Prospective cohort study of postmenopausal women. Cancer Epidemiol Biomarkers Prev. 2016 Jan; 25(1):43-50.

https://doi.org/10.1158/1055-9965.EPI15-0750

40. Sfreddo CS, Maier J, David SCD, Susin $\mathrm{C}$, Moreira $\mathrm{CHC}$. Periodontitis and breast cancer: A case-control study. Community Dent Oral Epidemiol. 2017 Dec;
45(6):545-51.

https://doi.org/10.1111/cdoe.12318

41. Shi $T$, Min M, Sun $C$, Zhang $Y$, Liang $M$, Sun $Y$. Periodontal disease and susceptibility to breast cancer: A metaanalysis of observational studies. $J$ Clin Periodontol. 2018 Sep; 45(9): 1025-33. https://doi.org/10.1111/jcpe.12982

42. Nwizu NN, Marshall JR, Moysich K, et al. Periodontal Disease and Incident Cancer Risk among Postmenopausal Women: Results from the Women's Health Initiative Observational Cohort. Cancer Epidemiol Biomarkers Prev. 2017 Aug; 26(8):1255-1265.

https://doi.org/10.1158/1055-9965.EPI17-0212

43. Amódio J, Palioto DB, Carrara HHA, Tiezzi DG, de Andrade JM, do Reis FJC. Oral health after breast cancer treatment in postmenopausal women. Clinics (Sao Paulo). 2014 Oct; 69(10):706-708. https://doi.org/10.6061/clinics/2014(10)1 0

44. Junjie X, Songyao J, Minmin S, et al. The association between Toll-like receptor 2 single-nucleotide polymorphisms and hepatocellular carcinoma susceptibility. BMC Cancer. 2012; 12:57. https://doi.org/10.1186/1471-2407-12-57

45. Lew JQ, Freedman ND, Leitzmann MF, et al. Alcohol and Risk of Breast Cancer by Histologic Type and Hormone Receptor Status in Postmenopausal Women: The NIH-AARP Diet and Health Study. Am J Epidemiol. 2009 Aug 1; 170(3):308-317.

https://doi.org/10.1093/aje/kwp120

46. Reynolds P, Hurley S, Goldberg DE, et al. Active smoking, household passive smoking, and breast cancer: evidence from the California Teachers Study. J Natl Cancer Inst. 2004 Jan 7; 96(1):29-37. https://doi.org/10.1093/jnci/djh002

47. Cui $Y$, Miller AB, Rohan TE. Cigarette smoking and breast cancer risk: update of a prospective cohort study. Breast Cancer Res Treat. 2006 Dec; 100(3):293-9. https://doi.org/10.1007/s10549-0069255-3

48. California Environmental Protection Agency: Air Resources Board. Proposed Identification of Environmental Tobacco Smoke as a Toxic Air Contaminant. 
UCSF: Center for Tobacco Control Research and Education. 2005. https://escholarship.org/uc/item/8hk6960 q

49. Breast Cancer Family Registry; Kathleen Cuningham Consortium for Research into Familial Breast Cancer (Australasia); Ontario Cancer Genetics Network (Canada). Smoking and risk of breast cancer in carriers of mutations in BRCA1 or BRCA2 aged less than 50 years. Breast Cancer Res Treat. 2008 May; 109(1):67-75.

https://doi.org/10.1007/s10549-0079621-9

50. Conway K, Edmiston SN, Cui L, et al. Prevalence and spectrum of p53 mutations associated with smoking in breast cancer. Cancer Res. 2002 Apr 1; 62(7):1987-95.

51. Perera FP, Estabrook A, Hewer A, et al. Carcinogen-DNA adducts in human breast tissue. Cancer Epidemiol Biomarkers Prev. 1995 Apr-May; 4(3):233-8.

52. Harris CC. Interindividual variation among humans in carcinogen metabolism, DNA adduct formation and DNA repair. Carcinogenesis. 1989 Sep; 10(9):1563-6.

https://doi.org/10.1093/carcin/10.9.1563

53. Ambrosone CB, Freudenheim JL, Graham S, et al. Cigarette smoking, Nacetyltransferase 2 genetic polymorphisms, and breast cancer risk. JAMA. 1996 Nov; 276(18):1494-501.

54. Rosenberg LU, Magnusson C, Lindström E, Wedrén $S$, Hall $P$, Dickman PW. Menopausal hormone therapy and other breast cancer risk factors in relation to the risk of different histological subtypes of breast cancer: a case-control study. Breast Cancer Res. 2006; 8(1):R11. https://doi.org/10.1186/bcr1378

55. Pierce JP, Patterson RE, Senger CM, et al. Lifetime cigarette smoking and breast cancer prognosis in the After Breast Cancer Pooling Project. J Natl Cancer Inst. 2014 Jan; 106(1):djt359. https://doi.org/10.1093/jnci/djt359

56. Hecht SS. Tobacco smoke carcinogens and breast cancer. Environ Mol Mutagen. 2002; 39(2-3):119-26. https://doi.org/10.1002/em.10071
57. Kalantari-Dehaghi M, Parnell EA, Armand T, Bernard HU, Grando SA. The nicotinic acetylcholine receptor-mediated reciprocal effects of the tobacco nitrosamine NNK and SLURP-1 on human mammary epithelial cells. Int Immunopharmacol. 2015 May; 29(1):99104.

https://doi.org/10.1016/j.intimp.2015.04.0 41

58. Pluchino LA, Wang HC. Chronic Exposure to Combined Carcinogens Enhances Breast Cell Carcinogenesis with Mesenchymal and Stem-Like Cell Properties. PLOS One. 2014; 9(11): e108698.

https://doi.org/10.1371/journal.pone.0108 698

59. Siriwardhana N, Choudhary S, Wang $\mathrm{HC}$. Precancerous model of human breast epithelial cells induced by NNK for prevention. Breast Cancer Res Treat. 2008 Jun; 109(3):427-41. https://doi.org/10.1007/s10549-0079666-9

60. Lee $\mathrm{CH}$, Huang $\mathrm{CS}$, Chen $\mathrm{CS}$, et al. Overexpression and activation of the alpha9-nicotinic receptor during tumorigenesis in human breast epithelial cells. J Natl Cancer Inst. 2010 Sep; 102(17):1322-35.

https://doi.org/10.1093/jnci/djq300

61. Hecht SS. Tobacco carcinogens, their biomarkers and tobacco-induced cancer. Nat Rev Cancer. 2003 Oct; 3(10):733-44. https://doi.org/10.1038/nrc1190

62. Firozi PF, Bondy ML, Sahin AA, et al. Aromatic DNA adducts and polymorphisms of CYP1A1, NAT2, and GSTM1 in breast cancer. Carcinogenesis. 2002 Feb; 23(2):301-6. https://doi.org/10.1093/carcin/23.2.301

63. Hecht SS. Progress and challenges in selected areas of tobacco carcinogenesis. Chem Res Toxicol. 2008 Jan; 21(1):160-71. https://doi.org/10.1021/tx7002068

64. Schuller HM, Plummer HK 3rd, Jull BA. Receptor-mediated effects of nicotine and its nitrosated derivative NNK on pulmonary neuroendocrine cells. Anat Rec A Discov Mol Cell Evol Biol. 2003 Jan; 270(1):51-8. https://doi.org/10.1002/ar.a.10019 
65. Zhao Y. The Oncogenic Functions of Nicotinic Acetylcholine Receptors. J Oncol. 2016; 2016:9650481. https://doi.org/10.1155/2016/9650481

66. Gupta N, Pal M, Rawat S, et al. Radiation-induced dental caries, prevention and treatment - A systematic review. Natl J Maxillofac Surg. 2015 JulDec; 6(2):160-166.

https://doi.org/10.4103/09755950.183870

67. Juozaitytè

\section{E, Aleknavičius}

E, Jančiauskienè $R$, et al. Guidelines for diagnostics and treatment of aromatase inhibitor-induced bone loss in women with breast cancer: a consensus of Lithuanian medical oncologists, radiation oncologists, endocrinologists, and family medicine physicians. Medicina (Kaunas). 2014; 50(4):197-203. https://doi.org/10.1016/j.medici.2014.09. 004

Conflicts of interest: The author declared no conflicts of interest related to this work.

\section{Corresponding author:}

Dr. Neelam Das

Assistant Professor, Department of Periodontology Rama Dental College Hospital \& Research Centre 208024

Kanpur, Uttar Pradesh, India E-mail: dasneelam423@gmail.com Telephone: +9190053 05242

This is an open access article distributed under the Creative Commons AttributionNoncommercial-NoDerivatives 4.0 International (CC BY-NC-ND 4.0) License. 